\title{
A review of fatigue in fishermen: a complicated and underprioritised area of research
}

\author{
Annbjørg S. á Høvdanum ${ }^{1}$, Olaf C. Jensen², \\ Guðrún Petursdóttir ${ }^{3}$, Ingunn Marie Holmen ${ }^{4}$ \\ ${ }^{1}$ Department of Occupational Medicine and Public Health, The Faroe Islands Health System, \\ Tórshavn, The Faroe Islands \\ ${ }^{2}$ Centre of Maritime Health and Society, Institute of Public Health, University of Southern Denmark, Esbjerg, Denmark \\ ${ }^{3}$ University of Iceland, Institute of Sustainability and Interdisciplinary Studies, Reykjavik, Iceland \\ ${ }^{4}$ SINTEF Fisheries and Aquaculture, Trondheim, Norway
}

\begin{abstract}
Background: Fatigue in fishing has been a highly underprioritised area of research, even though fatigue has been found to be the largest single contributing factor in accidents.

Aim: The aim of this article/paper is to provide an overview of the research conducted on fatigue in fishermen up to date, in order to establish a starting point for further research in this area.

Materials and methods: The review is mainly based on journal articles from PubMed, Google Scholar, International Maritime Health, Science Direct and some relevant articles links were also followed.

Results: The research revealed that only 5 articles have been published concerning fatigue in fishermen. The articles all confirmed that fatigue is a serious health and safety issue among fishermen, and that further research therefore is warranted.

Conclusions: Only 2 of the 5 studies of fishermen's fatigue used objective measures and in one of these, the sample size was small ( $n=19$ ), effectively limiting the statistical analysis and its application. Further research using larger samples is needed, preferably with a mix of objective and subjective measures, whereof some of the questions should be scenario based and some should be from standardised questionnaires. Greater understanding is also needed to assess how much of the variance in fatigue is attributable to e.g. length of trip, hours of work without rest, and type of job and specific tasks. A greater understanding of the similarities and differences between acute and long-term fatigue is also needed.
\end{abstract}

Int Marit Health 2014; 65, 3: 166-172)

Key words: fishermen, fatigue, sleepiness

\section{INTRODUCTION}

In the International Maritime Organisation guidelines on fatigue, cited in [1], fatigue is defined as "A reduction in physical and/or mental capability as the result of physical, mental or emotional exertion which may impair nearly all physical abilities including: strength; speed; reaction time; coordination; decision making; or balance." (p. 4).

Reduction of sleep length to 6 or $4 \mathrm{~h}$ for 14 days causes cognitive impairments comparable to 2 days of total sleep deprivation [2].
Many of the factors that are considered normal within the seafarer's occupation, such as long working hours, sleep disturbance and disturbed sleep rhythm, night work, harsh working conditions such as noise, ship motions and more, are factors that are commonly associated with fatigue. As early as 1971 fatigue was postulated to be a likely causal factor for many fatal personal accidents and has previously been identified as a major factor affecting accident rates [3, 4]. Reports indicate that fishermen work 24-96 h or more with little or no restorative sleep [5]. Thus on these terms, fatigue 
is unavoidable in this occupational sector. Long working hours is a common theme in transport sectors, e.g. [6] and aviation accident reports often cite fatigue as a main cause of the accident $[7,8]$. The awareness of the increased accident risk in the transport sector, has led to development and use of computerised mathematical process models, dual-models and 3-process models for predicting level of fatigue and its effect on cognitive functions, e.g. alertness/performance in daily life, for navy, airline and railway applications [9-11] as well as multimodal fatigue measure assessment for measuring early onset of drivers fatigue [12], but so far these have not been implemented in the fishing industry.

Despite the growing awareness of the negative effects of fatigue in the transport sector, fatigue at sea has been much less studied, than other modes of transport or safety-critical industries [13] and especially with regards to fishing. Seafarers fatigue is a contributing factor in $16 \%$ of critical vessel accidents and in 33\% of personal injury accidents across all types of maritime operations [14].

Results from meta-analysis show that the majority of shift workers favour 8-h shifts over longer shifts [15]. Furthermore, work periods longer that $8 \mathrm{~h}$, or series of shifts also increases the risk of accidents and the risk increases with time $[13,16]$.

Although the rate of fatal incidents has decreased by around 50\% in the time period 1980-2010 [17] the fatal injuries at sea more remain far frequent than ashore, with the incidence rate being 25 to 50 and up to 120 times higher (United Kingdom) [17].

From the literature on seafarers, among the most commonly recognised and documented causes of fatigue are poor quality of rest, excessive workload, noise and interpersonal relationships [18]. In some countries working hours for fisheries workers are not regulated by law as they are for workers ashore, and long working hours and lack of rest periods during fishing are problematic [19].
Although major improvements have been accomplished in safety by better education and training, in addition to major technological improvements, human physiology and psychology are the variables that have remained unchanged and are still the biggest challenge when it comes to working irregular hours, such as shift work or long hours, which often result in fatigue. The focus of this study is to review the current literature on fishermen's fatigue and the adverse effects it has on the working individual's cognitive functions, and the safety issues fatigue can cause for the individuals in this occupational group, their co-workers and the safety of the ship.

\section{MATERIALS AND METHODS}

The PubMed and Science Direct databases, Google Scholar, and the International Maritime Health were searched with key words fatigue, sleepiness and fishermen, some relevant articles links were also studied. Only articles about fishermen's fatigue are included in the actual review, but findings from the literature of merchant seafarers is also cited, as despite many differences, some of the challenging factors in working at sea are universal: e.g. long working hours, being isolated from their family, friends and social life, and both groups having to deal with many factors that they cannot influence, such as weather and noise.

\section{RESULTS}

The search in the databases resulted in only 5 articles on fishermen's fatigue or sleepiness, all produced within the last 11 years, demonstrating the lack of research on fatigue in this occupational group (Table 1). Of these 5 papers one mainly outlined the need for research on fatigue in fisheries. It concludes that fatigue in fisheries is unquestionably a problem that needs to be addressed [20].

Table 1. Summary of studies of fatigue in fishermen

\begin{tabular}{|c|c|c|c|c|c|}
\hline $\begin{array}{l}\text { Year } \\
\text { published }\end{array}$ & Authors & Location & $\begin{array}{l}\text { Period of data } \\
\text { collection }\end{array}$ & No of subjects & Data collection method \\
\hline 2011 & $\begin{array}{l}\text { Salyga and } \\
\text { Kušleikaitè }\end{array}$ & Lithuania & $\begin{array}{l}\text { Nov-Dec, } \\
2007\end{array}$ & $\begin{array}{l}\text { 932, wherof only } 532 \text { responded to } \\
\text { the fatigue part here of } 301 \text { fishermen }\end{array}$ & Questionnaire \\
\hline 2010 & Allen et al. & $\begin{array}{l}\text { United } \\
\text { Kingdom }\end{array}$ & 2005 & 81 & Questionnaire \\
\hline 2008 & $\begin{array}{l}\text { Gander } \\
\text { et al. }\end{array}$ & $\begin{array}{l}\text { New } \\
\text { Zealand }\end{array}$ & 2005 & 20 & $\begin{array}{l}\text { Sleep diaries, sleep quality question- } \\
\text { naire, sleepiness questionnaire (KSS), } \\
\text { actiwatchs to monitor movement } \\
\text { (analysed using sleepwatch) }\end{array}$ \\
\hline 2004 & Ólafsdóttur & Iceland & $\begin{array}{l}\text { Oct-Dec, } \\
2002\end{array}$ & $\begin{array}{l}112 \text { of whom } 24 \text { were randomly } \\
\text { selected to participate in sleep } \\
\text { measurement study }\end{array}$ & $\begin{array}{l}\text { Questionnaires and activity monitor } \\
\text { watches, for assessing sleep patterns }\end{array}$ \\
\hline 2003 & Conway & NA & NA & NA & NA \\
\hline
\end{tabular}

NA - not applicable; KSS - Karolinska Sleepiness Scale 
Table 2 includes the following studies.

Allen et al.'s [21] study of fishermen was the first study of its kind. Eighty one British fishermen of whom almost all were males and most working on small fishing vessels took part in the survey. The workers were tested on a shortened version of the questionnaire that was used in the Cardiff seafarers' fatigue project [22]. The results suggested that fatigue is a big problem in the fishing population. The longest continuous duty was $14 \mathrm{~h}$.

The Sąlyga and Kušleikaitè (2011) [23] study included fishermen and seafarers in general. It looked at factors that influenced psychoemotional strain and fatigue, and the relationship of these factors with health complaints at sea among Lithuanian seafarers. They found psycho-emotional strain to increase the risk of fatigue and that working conditions highly influenced strain and fatigue.

Two of the 5 studies contained objective measures. Gander et al. (2008) [24] found no significance in differences in length of sleep periods on land and at sea $(6.7 \mathrm{~h}$ vs. $5.9 \mathrm{~h}$ ), sleep efficiency (days at home $<70 \%=\mathrm{N} 12.6$ vs. days at sea $<70 \%=\mathrm{N} 16.5$ ) or pre-sleep according to the Karolinska Sleepiness Scale. However, the results showed that longer trips during the peak season increased the risk of performance impairment due to greater cumulative sleep loss [24].

Ólafsdóttir (2004) [25] examined the effects of shift work on wellbeing and sleep, with emphasis on fishermen. First is a review of the effects of shift work on workers in general, pointing out that shift work affects people differently. Those who are early risers and go to bed early (type A people) find it generally harder to adapt to shift work than those who stay up late and sleep in. Also, age plays a role, as those over 40 find it more difficult to adapt to shift work than younger people.

In the second half of the report, Ólafsdóttir [25] presents the results of studies on sleep patterns, sleep quality and wellbeing of fishermen working on a 6-h shift-systems ( $N=112$ and $N=17$ ) for questionnaires and physical activity measurements. The study is based on 3 types of questionnaires and a sleep recording study.

Results from the questionnaire "Model of Human Occupation" or "health-related life satisfaction" showed that: 1) officers experience stress from having to deal with conflicting demands, for the company on one hand and the crew on the other. 2) Noise, high room temperature and poor ventilation of the sleeping quarters increase psychological pressure and reduce sleep quality, which builds up fatigue and increases the risk of accidents. The quality of the bed is important; changing to new mattresses in this study prolonged sleep by 36 min on average. 3) Fishermen are under strain due to difficult working conditions, including repetitive motion, uneven temperatures, heavy workloads etc.
In more detail, Ólafsdóttir reports [25] that a great majority of the fishermen claimed that they liked their work (66\%), were interested in it (88\%) and felt that they contribute importantly to the company (91\%). In general, more than 3 out of 4 (77\%) fishermen were content with their work. Social factors, such a leadership style, positive feedback from superiors, etc. had a major impact on the well-being of the workers.

Regarding psychological factors within the last 6 months, $18 \%$ had experienced anxiety, 33\% depression and about $44 \%$ a sense of fatigue, with noticeable physical and psychological stress symptoms.

Most claimed that they coped well with the shift work (88\%), yet $47 \%$ stated that it had significant effects on their sleep, and $90 \%$ would prefer to work daytime rather than shift work. On 6-h shifts more than $90 \%$ slept on average $4 \mathrm{~h}$ on the first free-shift, and only $2-3 \mathrm{~h}$ on the next. More than half did not feel fully rested when waking up and felt sleepy during the day (3-5 times a week or more); of these, $59 \%$ were on the longer trips, and $47 \%$ of those on shorter trips. Furthermore, 3-5 days a week or more: one out of 5 woke up because of aches and pains, $41 \%$ had troubles with snoring, 66\% experienced stiffness after sleep, and 20\% experienced serious sleeping disturbances.

Workers on night-shift slept worse than those on day-shift, and "activity-monitors" showed that mates frequently dozed briefly off while on duty, which can seriously cause accidents. Such incidences occurred most frequently between 1:30 and 3 am, and between 14 and 15 pm. Approximately $20 \%$ of the fishermen had signs of insomnia with associated symptoms. Strain was most pronounced on-board the freezer trawlers.

\section{DISCUSSION}

A problem with fatigue studies, is that there is no "golden standard" [22]. One thing that can be confirmed from the reviewed studies is that they support the general agreement of other researchers in the field, that long working hours increase the risk of fatigue, accident and ill health [13]. However, fatigue is a complex problem, and that factors causing fatigue are not equal in "weight" and that there is a positive association between number of risk factors and increased fatigue [23, 26]. Fatigue is also the strongest single risk factor that was positively associated with decreased cognitive performance and health outcomes, accounting for $10-14 \%$ of the variance. These findings were also reaffirmed in Sąlyga and Kušleikaitè (2011) study [23].

Furthermore, after categorising the factors it was found that more organisational factors were associated with acute fatigue, while long term fatigue was more associated with psychosocial work characteristics [26].

Allen et al. [21] highlight the occupational risk that, fatigue is to the health and safety in the occupation of com- 


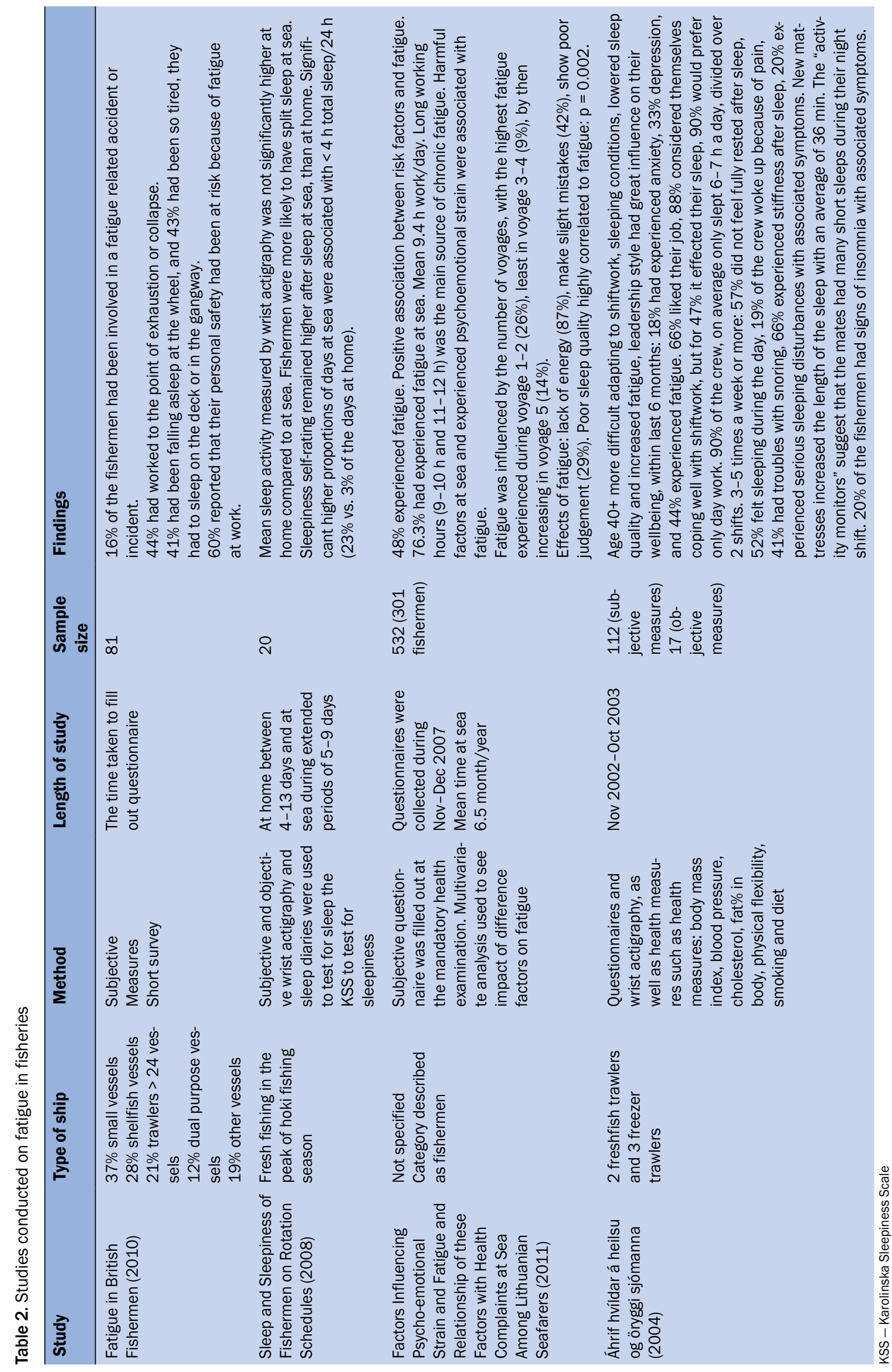


mercial fishing. In contrast to most studies conducted on seafarers, this study used scenario-relevant questions and this helped to make the concept of fatigue palpable, and gives more insight into the magnitude of fatigue and the high accident-risk outcomes fatigue can cause if enough of risk-behaviours and unfortunate incidents are present simultaneously.

However, the phrasing in the questionnaire does not offer information regarding the frequency of the problem. Furthermore, the sample was a small convenience sample, selected from accessibility, with the majority being from workers of smaller fishing vessel's (see Table 2 for details). Thus the results cannot be generalised to the United Kingdom fishing fleet, or internationally.

No control group was used, and the small sample size did not allow division into subgroups, although groups have been shown to differ in their expression of fatigue at sea. These are assumed to be caused by factors such as different type of fleet, nationality, work schedule, working tasks and patterns imposing different environmental, psychological and physical demands on the individual [25, 27]. Additionally, great inter-individual variability with regards to sleep and sleepiness has also been found [24, 28]. Despite methodological limitations, the fact that $41 \%$ of the sample reported having fallen asleep at the wheel supports the argument that fatigue should be considered a key health and safety risk factor for fishermen. Furthermore, $81 \%$ of the fishermen felt, that the adverse effects of fatigue, increased the longer they were at sea. This is also in line with sleep deprivation studies [29, 30].

Unlike the Allen et al. (2010) [21], Sąlyga and Kušleikaitè (2011) [23] asked about frequency; e.g. "how often do you feel sleepy during work?" About half of the men experienced fatigue during the voyages. The strongest source of chronic fatigue was long working hours. Interestingly, working the longest hours over $12 \mathrm{~h}$ was less significantly associated with fatigue, than working 7-12 $\mathrm{h}$. This might be because the fatigue reduces people's ability to evaluate their own fatigue and its effects. This is at best a guess and needs further studies. Still $18 \%$ of the participants reported never to gain recuperation after fatigue. A weakness of the study was that it included both merchant sailors and fishermen (30.6\%) and did not distinguish between these groups when doing the statistical analysis, although in the Cardiff research programme it was found that fatigue levels were reflected in ship type [22, 25]. As a consequence, it does not tell us whether there are some factors that are more dominant in one group than the other. The majority of studies of fatigue at sea focused on sleep as the primary factor for fatigue.

The lack of significant results in the study of Gander et al. [24] could be expected to be due to small sample size $(n=20)$ and high inter variability. Furthermore, split sleep does not offer the same restoration as when sleep is uninterrupted; thus a measure of total hours of sleep at sea compared to those at home might give an incorrect picture of the situation. This might also be part of the explanation for why sleepiness ratings remain higher after sleep at sea. For this kind of seasonal fishing, where long hours are almost unavoidable, Gander et al. [24] concluded that it is crucial that the fishermen are fully rested when beginning a new trip.

In the study of Ólafsdóttir (2004) [25], 90\% of the crew usually slept $4 \mathrm{~h}$ on the first shift, and $2-3 \mathrm{~h}$ on the next, giving a total of 6-7 h. Not getting a full $8 \mathrm{~h}$ continuous sleep means that they never get the deepest and most restorative part of the sleep, with the longest REM-sleep periods. Bearing in mind that sleep restrictions to continuous $6 \mathrm{~h}$ in 14 days was comparable in cognitive impairment to 2 days of total sleep deprivation [2]. The risk of accidents is doomed to be very high on ships doing longer trips, or shorter trips with short time in land. Ólafsdóttir's study [25] showed, that for workers on night shifts, who only had 2 days in land while unloading and then going back out again, the fatigue levels increased, as it usually takes more days to adapt to day rhythm than what they got. Her study also revealed numerous negative health effects on those who had been working shifts for 20 years or more. The fact that motion measurements indicated many short sleeps of mates during the watch period, makes it easier to accept findings showing that fatigue is considered a contributing factor in $82 \%$ of the groundings occurring between midnight and six in the morning and was also a major casual factor in the majority of collisions [31].

One factor that has led to confusion in fatigue research is the inter-person variability sometimes seen [32], as this, especially in smaller studies, can hide the actual main effect of fatigue. Therefore future studies should make the sample groups large enough not to be disturbed by individual differences. Also further studies are needed on personal variables, identifying which personality types are best fitted and most vulnerable.

A challenge and one of the frightening dangers about fatigue is that people's ability to judge their own level of fatigue is generally poor [1]. In studies comparing sleep loss with alcohol intoxication, it was found that after $17 \mathrm{~h}$ of wakefulness, performance decreased to a level equivalent to a blood alcohol concentration (BAC) of $0.05 \%$ and after $24 \mathrm{~h}$, performance decreased to a BAC of $0.10 \%[33,34]$.

\section{CONCLUSIONS}

The increased focus on fatigue at sea within the last decade has highlighted the threat that fatigue is to safety [14, 31] and the workers' health [25]. Progress has also been made [1], 
with large reduction in accident rates, presumably as a results of safety training and safety equipment [17]. However, despite reductions in accidents, we are still far from understanding and addressing the fatigue part of the problem sufficiently.

With only 5 studies of fatigue in fishermen, the current review demonstrates the immense need for research on fatigue in fishermen. All studies concluded that fatigue is a risk to safety.

A field study with a large enough sample to avoid disruption of inter-personal variations, and that also uses a repeated within subject comparison design, with both objective and subjective measures is needed, whereof the subjective measures should include both scenario-based questions and validated questionnaires. Preferably the studies should differentiate between sub-groups and under-groups within these groups, in order to get at better understanding of how much of the variance in fatigue is due to length of trip, hours of work without rest, type of job and specific tasks, etc. The literature also suggests differences in how acute and long-term fatigue is expressed $[13,23,24]$. Therefore this also needs further studies in order to improve understanding of which factors cause acute and long-term fatigue, and to what extent these two are task related or time related. And at last to test what the possible outcome differences of acute fatigue and long-term fatigue are.

\section{ACKNOWLEDGEMENTS}

I would like to express my very great appreciation to Dr Olaf $\mathrm{C}$. Jensen for his valuable and constructive suggestions during the planning and development of this research work. His willingness to give his time so generously has been very much appreciated.

I would also like to thank some of the staff of the following organisations for trusting in me to conduct this review on the behalf of our research group.

- Syddansk Universitet, Esbjerg, Danmark, Dr Olaf C. Jensen;

- SINTEF Fisheries and Aquaculture, Trondheim, Norge, Research Manager Ingunn Marie Holmen;

- University of Iceland, Reykjavik, Director Dr Gudrun Petursdottir;

- Fiskeriets arbejdsmiljøråd, Danmark, Flemming N. Christensen;

- Last but not least, Norden-Grant, for giving economical support in order to make this research possible.

\section{REFERENCES}

1. International Maritime Organisation. Guidance on fatigue and Mitigation Management. I: \circ \msc \1014.doc. 2001.

2. Van Dongen HP a, Maislin G, Mullington JM, Dinges DF. The cumulative cost of additional wakefulness: dose-response effects on neurobehavioral functions and sleep physiology from chronic sleep restriction and total sleep deprivation. Sleep 2003; 26: 117-126.

3. Schilling RS. Hazards of deep-sea fishing. Br J Ind Med 1971; 28: 27-35.

4. Roberts SE. Occupational mortality in British commercial fishing 1976-95. Occup Environ Med 2004; 61: 16-23.

5. Committee on Fishing Vessel Safety (1991).

6. Sabbagh-Ehrlich S, Friedman L, Richter ED. Working conditions and fatigue in professional truck drivers at Israeli ports. Inj Prev 2005; 11: $110-114$

7. Flightdutytimes. Http://www.flightdutytimes.eu/?page_id=109.

8. Transport SafetyBoard of Canada (2011).

9. Gunzelmann G, Byrne MD, Gluck KA, Moore LR. Using computational cognitive modeling to predict dual-task performance with sleep deprivation. Hum Factors 2009; 51: 251-260.

10. Akerstedt T, Folkard S, Portin C. Predictions from the three-process model of alertness. Aviat Space Environ Med 2004; 75 (3 suppl.): A75-A83.

11. Van Dongen HP a, Mott CG, Huang J-K, Mollicone DJ, McKenzie FD, Dinges DF. Optimization of biomathematical model predictions for cognitive performance impairment in individuals: accounting for unknown traits and uncertain states in homeostatic and circadian processes. Sleep 2007; 30: 1129-1143.

12. Jagannath $M$, Balasubramanian V. Assessment of early onset of driver fatigue using multimodal fatigue measures in a static simulator. Applied Ergonomics 2014; 45: 1140-1147.

13. Allen $P$, Wadsworth $E$, Smith A. Seafarers' fatigue: a review of the recent literature. Int Marit Health 2008; 59: 81-92.

14. Raby M, Lee JD. Fatigue and workload in the maritime industry. In: Hancock PA, Desmond PA (eds.). Stress workload and fatigue. Lawrence Erlbaum Associates Mahwah, New Jersey 2001: 566-578.

15. Knauth P. Extended work periods. Ind Health 2007; 45: 125-3616.

16. Wagstaff AS, Sigstad Lie JA. Shift and night work and long working hours - a systematic review of safety implications. Scand J Work Env Heal 2011; 37: 173-185.

17. Jensen OC, Petursdottir G, Holmen IM, Abrahamsen AS, Lincoln J. A review of fatal accident incidence rate trends in fishing. Int Marit Health 2014; 65: 1-6.

18. The IMO Assembly Resolution A.772 (18) On Fatigue Factors in Manning and Safety. http://www.imo.org/OurWork/HumanElement/ VisionPrinciplesGoals/Pages/Text-of-annex-to-resolution-A.772(18). aspx Cited:06.09.2014.

19. Bull N, Riise T, Moen BE. Occupational injuries to fisheries workers in Norway reported to insurance companies from 1991 to 1996. Occup Med (Lond) 2001; 51: 299-304.

20. Conway GA. Proceedings of the Second International Fishing Industry Safety and Health Conference 2003.

21. Allen P, Wellens B, Smith A. Fatigue in British fishermen. Int Marit Health 2010; 62: 154-158.

22. Smith A, Allen P, Wadsworth E. Seafarer Fatigue: The Cardiff Research Programme (Internet). Center for Occupational and Health Psychology, Cardiff University, UK, 2006.

23. Sąlyga J, Kušleikaitè M. Factors influencing psychoemotional strain and fatigue, and relationship of these factors with health complaints at sea among Lithuanian seafarers. Medicina (Kaunas) 2011; 47: 675-681.

24. Gander P, van den Berg M, Signal L. Sleep and sleepiness of fishermen on rotating schedules. Chronobiol Int 2008; 25: 389-398.

25. Ólafsdóttir L. Áhrif hvíldar á heilsu og öryggi sjómanna Rannsókn gerð̆ á íslenskum sjómönnum: Á vegum Samgönguráouneytisins. Maí 2004 Solarplexus ehf. 2004: 1-97. 
26. Wadsworth EJK, Allen PH, McNamara RL, Smith AP. Fatigue and health in a seafaring population. Occup Med (Lond) 2008; 58: 198-204.

27. Smith A, Lane T, Bloor M, Allen P, Burke A, Ellis N. Fatigue Offshore: Phase 2. The short sea and coastal shipping industry. Seafarers International Research Centre, 2003.

28. Van Dongen HP a. Shift work and inter-individual differences in sleep and sleepiness. Chronobiol Int 2006; 23: 1139-1147.

29. Mollicone DJ, Van Dongen HP a, Rogers NL, Banks S, Dinges DF. Time of day effects on neurobehavioral performance during chronic sleep restriction. Aviat Space Environ Med 2010; 81: 735-744.
30. Banks S, Van Dongen HP a, Maislin G, Dinges DF. Neurobehavioral dynamics following chronic sleep restriction: dose-response effects of one night for recovery. Sleep 2010; 33: 1013-1026.

31. Williamson a M, Feyer a M, Mattick RP, Friswell R, Finlay-Brown S. Developing measures of fatigue using an alcohol comparison to validate the effects of fatigue on performance. Accid Anal Prev 2001; 33: 313-326.

32. Marine Accident Investigation Branch (MAIB). Annual Report 2004.

33. Dawson D, Reid K. Fatigue, alcohol and performance impairment. Nature 1997; 388: 235.

34. Lamond N, Dawson D. Quantifying the performance impairment associated with fatigue. J Sleep Res 1999; 8: 255-262. 